\title{
Cyber Physical Systems for Smart Cities Development
}

\author{
M.A.Jabbar ${ }^{1}$, Shirina Samreen ${ }^{2}$, Rajanikanth Aluvalu ${ }^{3}$ Dr. K. Kiran Reddy ${ }^{4}$ \\ ${ }^{I}$ professor, Vardhaman College of Engineering, Hyderabad \\ ${ }^{2}$ CVSR College of Engineering, Hyderabad \\ ${ }^{3}$ Vardhaman College of Engineering, Hyderabad \\ ${ }^{4}$ Department of IT MLR Institute of Technology, Hyderabad \\ *Corresponding author E-mail: jabbar.meerja@gmail.com
}

\begin{abstract}
With the technological advances in ICT people are migrating to urban areas. Urbanization becomes a global phenomenon. By 2030, $60 \%$ of the population will live in urban. Development of smart cities is inevitable. Cyber Physical Systems (CPS) supports our day to day activities. With the emergence of CPS is becoming more important to smart cities. Smart cities can be viewed as large scale implementations of CPS. This paper throws some light on the concepts of CPS, Smart and the various challenges posed by CPS in implementing in smart cities.This paper also describes research directions for CPS .
\end{abstract}

Keywords: Smart city; Cyber Physical Systems; urbanization; ICT.

\section{Introduction}

With the technological advances in communication and computing, people are migrating to cities for better amenities, education, healthcare, and for employment .Urbanization becomes a global phenomenon. By 2030, $60 \%$ of the population will live in urban [1]. As per UN report, Indian population will grow to 814 million by 2050 and by 2030, urban population contribute to $75 \%$ of GDP [2]. By 2030, 41 megacities will have more than $12 \%$ world urban population [3]. As a result, cities are becoming "smart" to ensure economically viable and comfortable. Development of smart cities is inevitable.

Smart city is defined as a city which functions by integrating ICT, infrastructures, intelligent devices to ensure sustainability.

Cyber Physical Systems (CPS) supports our day to day activities. CPS and IOT allow devices to sense capture and process data. CPS are the integration of physical and computational systems.

Smart cities are large scale integration of CPS where sensors capture the cyber and physical components. Data gathered through sensors, processing of information makes CPS a key component in smart cities.

Existing ICT solutions are not fully required support for dynamically changing physical systems. CPS will bring necessary tools and mechanisms which support changes in physical systems which helps smart city ecosystems. This paper reviews key component of smart city i.e CPS and its technological trends.

Section 2 discuss about components of smart cities and challenges posed by smart cities in implementing and the concepts of cyber physical systems. Section 3 throws some light on CPS and smart cities. Concluding remarks are given in section 4.

\section{Related Terms}

\subsection{Smart Cities}

Cities can be regarded as reflecting a face of a country.

Smart city is a complex and an ultramodern urban area which addresses the needs of citizens.

According to the recent survey, the world population will rise to 8.5 billion by 2030 and 11.2 billion by 2050 .

Many cities in North America, Europe and Asia are adopting smart city concept.

Due to advancement of emerging technologies like big data, IOT and cloud computing leading to the creation of smart cities. Smart city is an integration of technological platform to address the following challenges [4].

1) Transportation

2) Health care

3) Traffic and mobility

4) Public safety

5) Municipal corporation services like sanitation, water management etc.

Smart city requirements are classified into two types

1) Operational

2) Application services [5]

Smart cities will have the following elements

Broadly Speaking Smart Cities Are 1) Sociable 2) Sensible 3)

Connectable 4) Accessible 5) Ubiquitous 5) Sharable [6].

According to frost and Sullivan research, there is a scope for $\$ 1.5$ trillion for smart city project globally.

Smart cities with integrated technology platform have to manage the following changes.

1) Urban flooding 
2) Health

3) Transportation

4) Traffic

5) Waste management

6) Environment and pollution

7) Water and electricity supply

8) E governance

9) Crime and public safety.

Various key parameters have been identified for smart cities. Few of them are
1) Smart citizen
2) Smart health care
3) Smart energy
4) Smart economy
5) Smart parking

Cities are the major contributors to environmental pollution. Innovative solutions are need of the hour to address environment, economic and societal problems which are faced by smart cities. Few of them are 1) Optimal management of energy resources 2) Decentralization of energy production 3) Integrated economic and business models 4) Transportation and environment 5) Safety and security 6) Tourism 7) Educational facilities 8) Citizens health Smart city model consists of following components are (Refer Figure 1) [7]
1. Smart economy
2. Smart people
3. Smart living
4. Smart environment
5. Smart governance and smart mobility

Essential components of smart city include
1) Broad band infrastructure
2) E-Governance
3) E-Services
4) Open government data
5) Infrasture

Design and implementation of smart city projects involve following technologies
1) Big data and Cloud Computing
2) Service Oriented Architecture (SOA)
3) Networking and IoT
4) Ubiquitous Computing

Various key parameters for smart cities are listed in table 1

Table 1: Key parameters for smart cities

\begin{tabular}{|c|c|c|}
\multicolumn{3}{|c|}{ Table 1: Key parameters for smart cities } \\
\hline Sl no & City & Parameters \\
\hline 1 & Barcelona & Smart parking \\
\hline 2 & New York & $\begin{array}{c}\text { Smart Street Lighting } \\
\text { Smart Traffic Management }\end{array}$ \\
\hline 3 & London & Smart technology \\
\hline 4 & Singapore & Smart Traffic Management \\
\hline
\end{tabular}




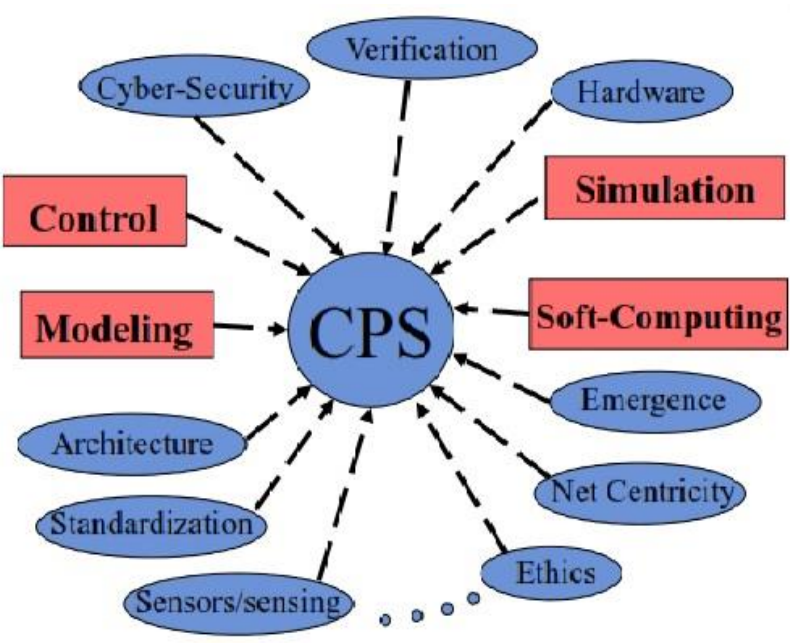

Figure 2: Challenges posed by CPS[8]

There are various advantages of adopting the CPS in smart city.

1) Service providers will provide enhanced services to citizens

2) Modernization of utility grid

3) Accessibility and usability of physical infrastructures will be improved.

4) CPS allows participatory governance.

\section{CPS and Smart city}

With the emergence of CPS is becoming more important to smart cities. Smart cities can be viewed as large scale implementations of CPS. However there are various challenges to adopt CPS in smart cities. The challenges for the CPS and smart city are

1) Heterogeneity of CPS

2) Large and complex networks

3) Limited resources and budget constraints [10]

4) Attacks on CPS and security issues.

5) Reliability

6) Data management

7) Real time [11]

ICT infrastructure is the backbone of smart city. CPS support openness and are required coordination of ICT[12]

Smart city parameters, CPS applications and effects of using CPS are shown in Table 2 [13].

Some of the applications areas of CPS for the development of smart cities are

1) Smart Industry

2) Smart Healthcare

3) Smart Energy:

4) Smart infrastructure

5) Smart mobility

Table 2: Smart city parameters, CPS applications and effects

\begin{tabular}{|c|c|c|}
\hline $\begin{array}{l}\text { Smart city parame- } \\
\text { ters }\end{array}$ & CPS application & Effects \\
\hline Smart governance & $\begin{array}{l}\text { E governance and } \\
\text { E democracy }\end{array}$ & $\begin{array}{l}\text { Quality and effective ser- } \\
\text { vices to citizens }\end{array}$ \\
\hline Smart security & $\begin{array}{l}\text { Coordination of } \\
\text { advanced surveil- } \\
\text { lance equipment }\end{array}$ & $\begin{array}{l}\text { Improves the quality of } \\
\text { living and reduces the } \\
\text { crimes }\end{array}$ \\
\hline Smart energy & $\begin{array}{l}\text { Smart grid tech- } \\
\text { nologies }\end{array}$ & Less consumption of fuels. \\
\hline $\begin{array}{l}\text { Smart transporta- } \\
\text { tion }\end{array}$ & $\begin{array}{l}\text { E mobility using } \\
\text { GPS }\end{array}$ & $\begin{array}{ll}\text { 1. } & \begin{array}{l}\text { Reduces gas } \\
\text { emissions }\end{array} \\
\text { 2. } & \begin{array}{l}\text { Reduces traffic } \\
\text { congestion }\end{array} \\
\text { 3. } & \begin{array}{l}\text { Diminishing } \\
\text { noise }\end{array}\end{array}$ \\
\hline
\end{tabular}

CPS is a combination of various engineering competencies like

1. Monitor and control organizational physical processes

2. spanning various application domains

3. integration of different technical and application domains

4. high degree of dependability

5. Require user involvement

6. Monitoring and optimizing performance

7. Be a interconnected and distributed and systems of systems[14]

Well-designed CPS will increase the comfort ability in the smart city, revitalize sites of urban production and increases the chances of entrepreneurial ship. The development of CPS is important for implementation of technologies for smart cities applications.

\section{Conclusion}

Cities can be regarded as reflecting a face of a country.

Due to advancement of emerging technologies like big data, IOT and cloud computing leading to the creation of smart cities. Development of smart cities is inevitable. Smart cities can be viewed as large scale implementations of CPS. This paper explores the concepts of smart city, CPS and how smart city will benefit from CPS, Certification and validation of CPS, security and privacy, and the various challenges posed by CPS in smart cities Welldesigned CPS will increase the comfort ability in the smart city, revitalize sites of urban production and increases the chances of entrepreneurial ship.

\section{References}

[1] www.un.org

[2] Smart cities mission statements and guidelines mission urban development guide of india, june 2015

[3] Christos G cassandra s, "smart cities as cyber phisical systems", Engineering, vol 2, pp 156-158(206)

[4] K V N Rajesh, "smart cities- An improvement not an option", CSI Communications,pp 14-17, may 2016

[5] Aloi G et al., "An evolutionary network architecture for smart and sustainable cities ", Trans.Emer.Telecom.TEchn 25(1),pp 21-40, 2014

[6] Jaokar A, "big data for smart cities", In smart cities industry summit, sep 25-26, 2012

[7] Comunications of the ACM, vol 59,no 8, august 2016

[8] Rodolfo Haber, "CPS: Researech and technological challenges", www.car.upm-csic.es, last accessed,2017

[9] Nishita kesswani et al., "CPS and smart cities", CSI communications, pp 29-30, 2017

[10] Ali asgar Ghaemi, "A cyber phisical system approach to smart city development ", in ieee intl.conf on smart grids and cities, pp 257 262, 2017

[11] Alessandro Zanni, "cyber phisical systems and smart cities developer works", IBM, 2015

[12] Broy, M. cengarle, M.A et.al, "CPS :imminent challenges in large scale complex IT systems, development operations and management ", springer, pp 1-28, 2012

[13] Matrina Frmhold -eisebith,"cyber phisical systems in smart cities mastering technological economics and social challenges smart cities, foundations, principles and applications", first edition, wiley and sons, pp 1-21, 2017

[14] http://www.cpse-labs.eu/cps.php 